\title{
Endoscopic Retrieval vs Observation in Cylindrical Battery Ingestion
}

\author{
Muhammad Bader Hammami, MD, ${ }^{1}$ Samer Alkaade, MD, ${ }^{1}$ Cyrus Piraka, MD, ${ }^{2}$ Jason R. Taylor, MD $^{1}$ \\ ${ }^{1}$ Division of Gastroenterology and Hepatology, Saint Louis University School of Medicine, St. Louis, MO ${ }^{2}$ Division of Gastroenterology and \\ Hepatology, Henry Ford Hospital, Detroit, MI
}

\begin{abstract}
Background: Battery ingestion, particularly in the pediatric population, has become more common since the development of button batteries. Consequently, formal recommendations regarding the management of this battery type have been developed. Larger cylindrical battery ingestion is less common, with fewer cases reported. As such, no clear practice guidelines have been developed for the management of cylindrical battery ingestion.

Case Report: We present a case of an incarcerated adult who ingested 2 AA batteries. One battery was retrieved endoscopically, but the second passed into the distal small bowel beyond endoscopic means of retrieval. The second battery passed spontaneously via the rectum after administration of laxatives and supportive care.

Conclusion: Our case and review of the literature demonstrate that nonsurgical, conservative management with close clinical monitoring is possible in a hospital setting after cylindrical battery ingestion. Cases with concerning clinical symptoms or a history of damage to the battery casing warrant endoscopic or surgical intervention.
\end{abstract}

Keywords: Endoscopy-digestive system, foreign bodies, ingestion, suicide-attempted

Address correspondence to Jason R. Taylor, MD, Division of Gastroenterology and Hepatology, Saint Louis University School of Medicine, 1402 S. Grand Blvd., St Louis, MO 63104. Tel: (314) 577-8764. Email: jason.taylor@health.slu.edu

\section{INTRODUCTION}

Battery ingestion, particularly in the pediatric population, has become more common since the development of button batteries. Consequently, formal recommendations regarding the management of this battery type have been developed. ${ }^{1}$ Larger cylindrical battery ingestion is less common, with fewer cases reported. As such, no clear practice guidelines have been developed for management of cylindrical battery ingestion. We present a case of an adult prison inmate who ingested 2 AA batteries in a suicide attempt, review the available literature and associated sequelae, and propose an approach to the management of patients presenting after the intentional ingestion of cylindrical batteries.

\section{CASE REPORT}

A 36-year-old male was transferred to our facility from prison after reporting that he had ingested 2 AA batteries 2 days prior to admission. He had a history of schizophrenia and a previously reported suicide attempt by ingestion of AA batteries that were endoscopically retrieved. The patient had no complaints on admission; he denied abdominal pain, nausea, vomiting, and other gastrointestinal (Gl) symptoms. His physical examination was without significant findings, including a nontender, nondistended abdomen and regular bowel sounds. Laboratory data were unremarkable. Abdominal $\mathrm{x}$-rays revealed 2 cylindrical structures superimposed on the mid upper abdomen consistent with the reported battery ingestion (Figure 1A).

Approximately 2 hours after the patient's presentation, upper Gl endoscopy revealed one AA battery in the gastric fundus (Figure 1B). The second battery was not seen on endoscopic examination up to the third portion of the duodenum, and no mucosal damage was apparent. An overtube was placed. The first battery was captured with a snare and retrieved through the overtube. After retrieval of the first battery, a second examination with a pediatric colonoscope was conducted. The pediatric colonoscope was advanced deep into the jejunum, at least $80 \mathrm{~cm}$ from the ligament of Treitz, without success in locating the second battery.

Repeat abdominal x-rays revealed the second battery in the distal ileum or proximal colon (Figure 1C). Meanwhile, the patient's psychiatric medications were adjusted, and he was started on a regular diet that he tolerated well. Daily abdominal x-rays (Figure 2) demonstrated the battery progressing from the proximal colon to the descending colon. He was administered a 10-ounce bottle of magnesium citrate and started on $17 \mathrm{~g}$ daily of polyethylene glycol 3350 on hospital day 4, resulting in regular bowel movements the following day. The patient defecated the battery on hospital day 7. His hospital course was otherwise unremarkable, and he was discharged back to the correctional facility. 

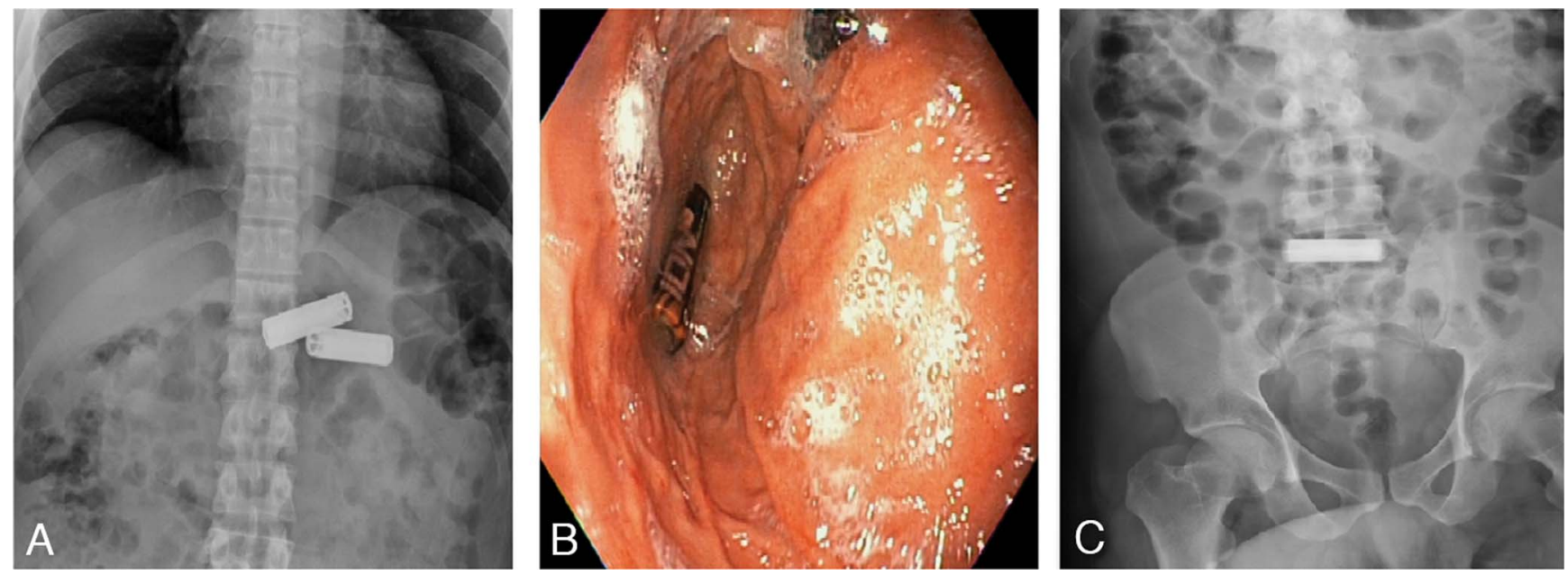

Figure 1. A. This supine anteroposterior view of the abdomen shows 2 cylindrical structures superimposing the right upper quadrant, likely in the gastric antrum (hospitalization day 1, prior to esophagogastroduodenoscopy [EGD]). B. Endoscopic image in retroflexion reveals an ingested battery in the gastric fundus. C. A cylindrical structure superimposing the mid lower abdomen represents the remaining ingested battery (hospitalization day 1, after EGD).

\section{DISCUSSION}

Ingestion of batteries has been well documented in the medical literature and at poison control centers for decades. However, the majority of the literature concerning battery ingestion deals with button batteries rather than with cylindrical batteries. In a 7-year study from the National Capital Poison Center in Washington, DC, individuals swallowing button batteries greatly outnumbered those ingesting cylindrical batteries $(2,320$ vs 62$){ }^{2}$

Button batteries are more likely to be swallowed either by accident or by a curious child. ${ }^{3}$ Button batteries may cause liquefactive necrosis, and perforation can occur rapidly when the battery lodges in the esophagus, leading to severe and potentially fatal complications. As such, formal guidelines have been developed and emphasize emergent removal of button batteries from the esophagus. ${ }^{1}$

On the other hand, given the larger size of cylindrical batteries, they are commonly ingested deliberately in the psychiatric population and by prison inmates. ${ }^{4,5}$ Most ingestions occur in patients 6-39 years of age. ${ }^{6}$ Cylindrical cells are typically alkaline-manganese or nickel-cadmium (rechargeable) and when ingested can cause corrosive and toxic damage. Such damage can occur if the integrity of the battery casing is deliberately damaged and can also occur from sustained acid attack from gastric contents for a period of weeks, rather than days, or as a result of battery leakage. Untersweg et al reported the case of a 4-year-old boy who sustained grade II-III esophageal burns from putting a leaking cylindrical battery to his mouth and sucking the caustic solution. ${ }^{7}$ The burns resulted in an esophageal stricture, necessitating frequent bouginages and placement of a jejunal tube for feeding.

The most comprehensive studies on battery-related exposures are based on cases reported to the National Battery Ingestion Hotline and US poison control centers. Litovitz conducted an 11-month review of the National Capital Poison Center at Georgetown University Hospital where 125 battery ingestions were reported. ${ }^{8}$ Only 6 of the ingested batteries were cylindrical; all passed through the GI tract spontaneously. Two cylindrical batteries were ingested by a 6 -year-old and a 12-year-old child. Both children remained asymptomatic and passed the batteries in 36-38 hours. The other 4 batteries were ingested by a 30 -year-old male convict who swallowed the batteries to avoid incarceration and subsequently reswallowed 3 of the excreted batteries with no reported adverse events. Litovitz and Schmitz next conducted a 7-year review. ${ }^{2}$ Of the 2,383 reported battery ingestion cases, only 62 were reported as cylindrical battery ingestions: 33 patients ingested $A A$ batteries, 26 patients ingested AAA batteries, 2 patients ingested $\mathrm{N}$ batteries, and 1 patient ingested a $\mathrm{C}$ battery. No other characteristics were reported. The Litovitz et al 18.25-year review reviewed 8,648 battery ingestion cases, 487 of which were cylindrical ingestions. ${ }^{9}$ The researchers did not report individual characteristics of the cylindrical battery ingestions, but statistics showed that at least $43 \%$ of them were intentional, suicidal, or associated with a neuropsychiatric disorder; another $6 \%$ were by incarcerated individuals. Additionally, $37.8 \%$ of cylindrical cell ingestions involved multiple cells compared with $8.7 \%$ of button cell ingestions.

We conducted a literature search in PubMed, Scopus, and Cochrane Library for the terms cylindrical, battery, and ingestion from database inception until September 17, 2017 and identified 15 case reports and 1 case series (a case written in the Spanish language was not included). We summarize these cases in the Table. ${ }^{10-25}$

Most reported cases involved patients who were asymptotic after ingestion. If symptoms did occur, they usually manifested as upper Gl complaints or abdominal pain. Unusual presentations include ST segment abnormalities on electrocardiogram and a grand mal seizure. ${ }^{10,18}$ All but one patient ${ }^{19}$ with a history of prior abdominal surgery required either surgical or endoscopic intervention for battery retrieval, possibly related to adhesions or dysmotility preventing the passage of the batteries. ${ }^{11,12,13,22,24}$ 


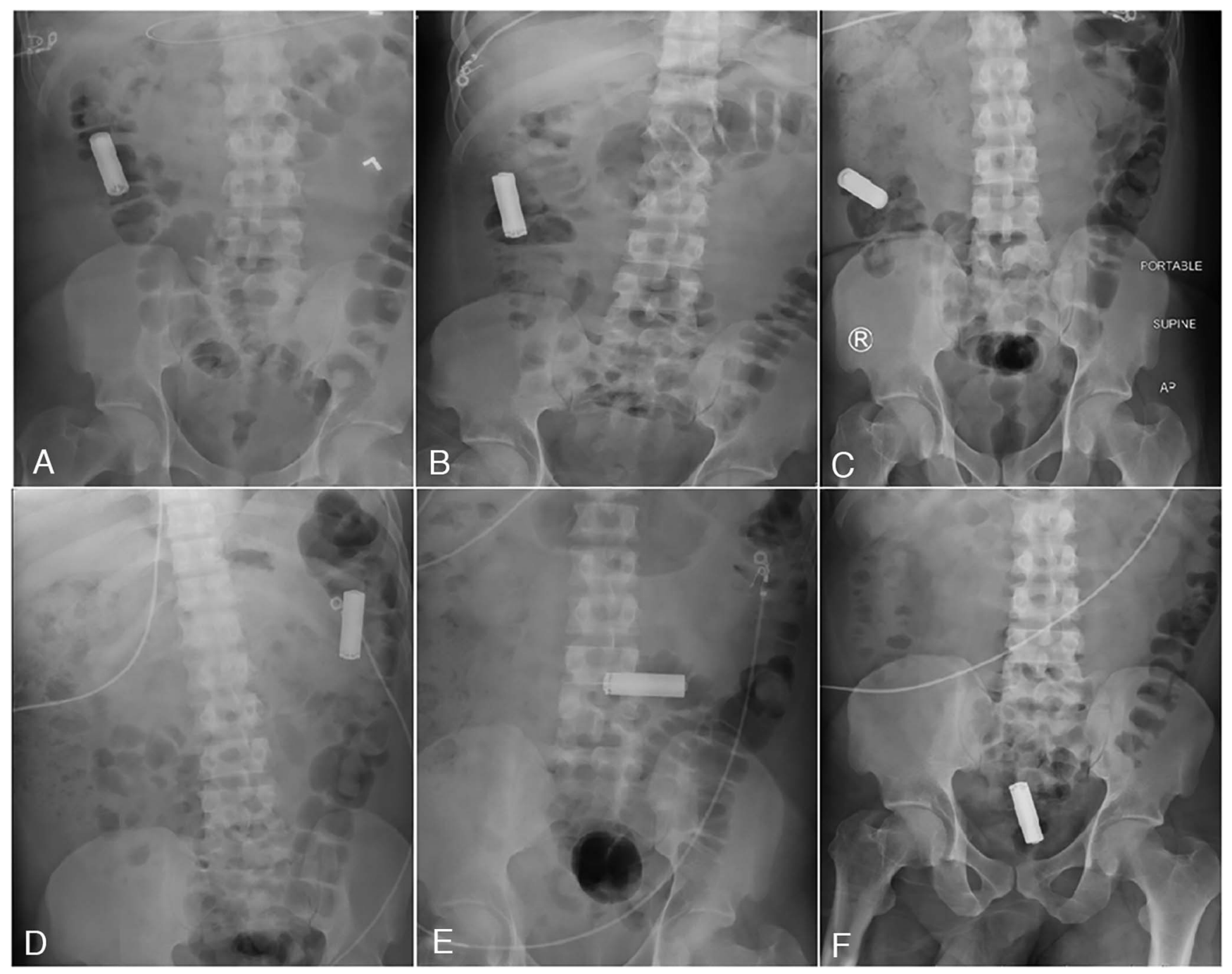

Figure 2. Supine anteroposterior views of the abdomen demonstrate the single ingested cylindrical structure advancing through the gastrointestinal tract (hospitalization days 2, 3, 4, 5, 6, and 7, respectively). A. Within the right upper quadrant and either in the distal ileum or proximal colon. B. Within the region of the ascending colon. $C$. Within the region of the ascending colon. D. Within the left mid abdomen and in the region of the descending colon. E. Within the region of the sigmoid colon. F. Projecting over the pelvis in the region of the rectum.

Several patients spontaneously passed the cylindrical batteries via the rectum. In the Hindley et al case series, 3 psychiatric patients swallowed cylindrical batteries and passed them with conservative management within 1-2 weeks, a fourth patient passed ingested batteries within 3-4 months, and a fifth patient required surgical extraction. However, the patient who required surgery, unlike the other 4 , had developed acute upper Gl pain. ${ }^{13}$

Our review revealed that in all cases with evidence of corrosive changes, leakage, or damage to the battery casing, patients were symptomatic or had evidence of mucosal damage. ${ }^{10,11,13,14,21,22}$ In 2017, Tien and Tanwar reported a case of a 3-battery ingestion that resulted in gastric ulcers and gastritis within 14 hours, despite the patient denying destruction of the battery cases. ${ }^{24}$ Our review of the abdominal $x$-rays provided with the case suggested distortion of the battery casing that would have explained the gastric find- ings. Two batteries were removed urgently from the stomach; the third had passed to the small bowel. Despite conservative management for 2 days with a laxative, urgent colonoscopy with planned terminal ileum intubation was attempted because of concern that the third battery would be impacted at the ileocecal (IC) valve. On endoscopy, the battery had passed the IC valve and was retrieved from the proximal right colon. Urgent colonoscopy may not have been indicated in this case, as the battery had passed the IC valve and therefore would have likely been passed without complication.

In a case from 2015, Hammad et al reported the case of a patient whose ingestion of 7 cylindrical batteries resulted in severe gastric ulcerations and erosions caused by the corrosive alkaline spilling from the eroded batteries, despite the patient being asymptomatic and the batteries being in his stomach for less than 12 hours. ${ }^{21}$ 


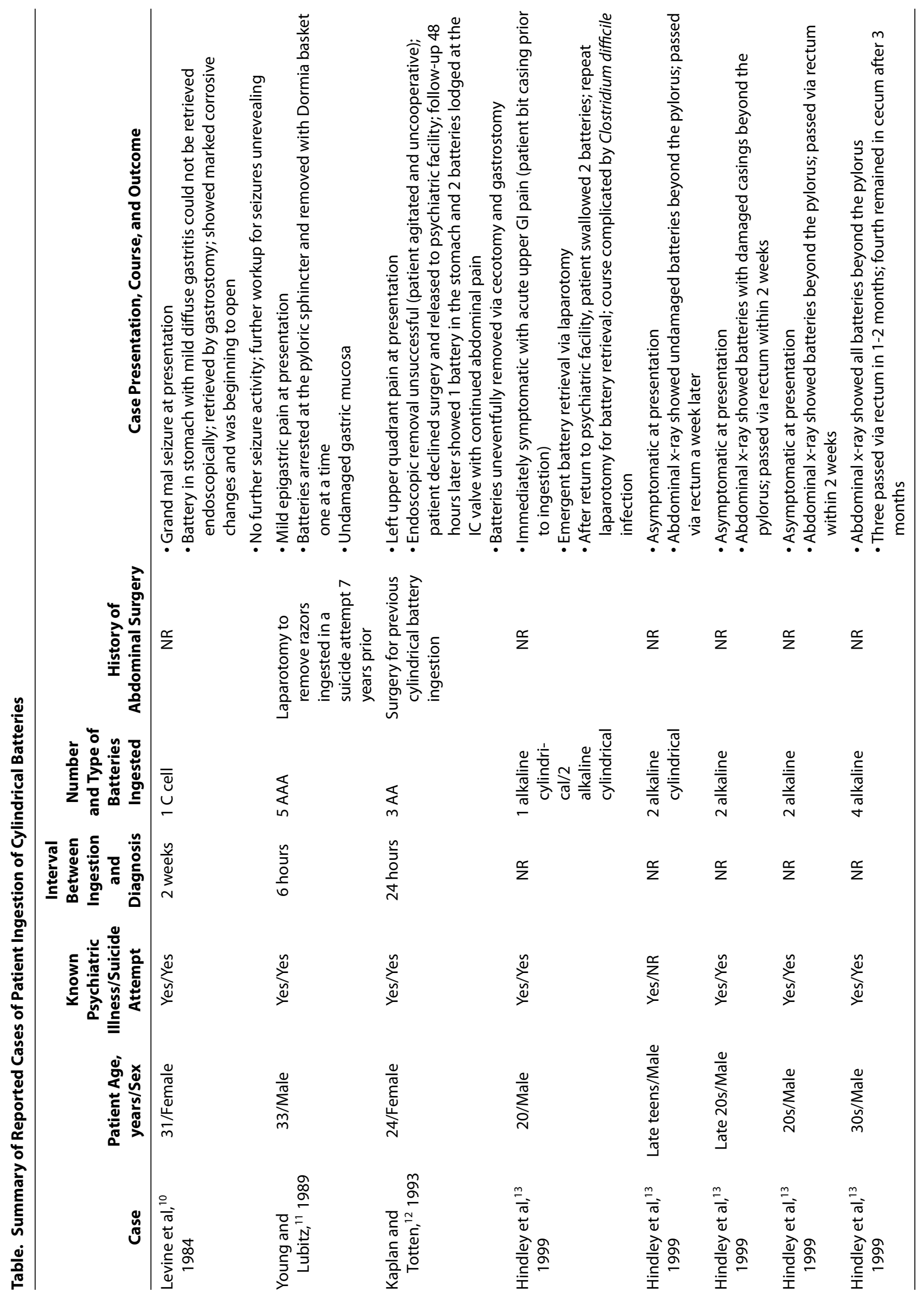




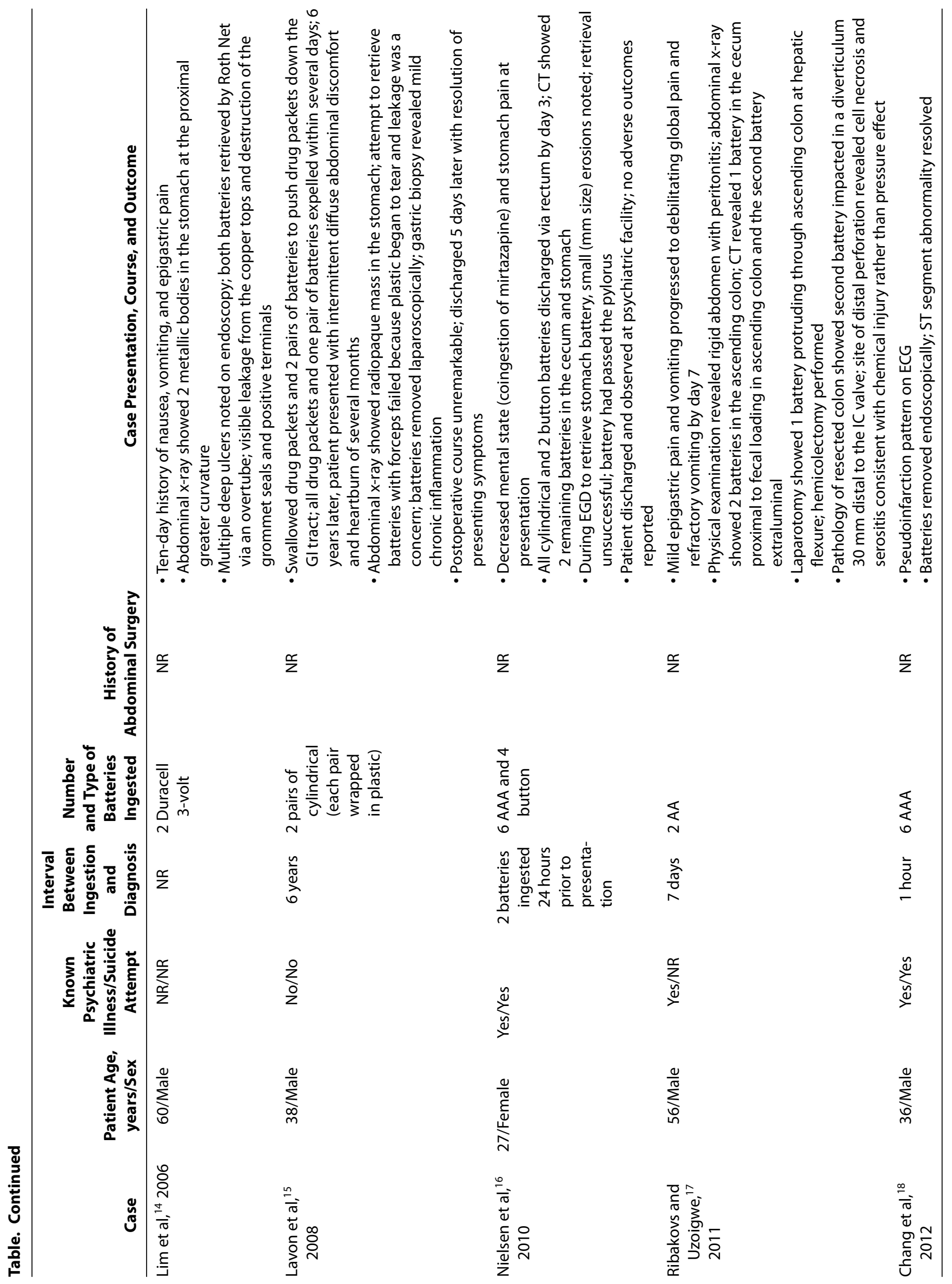




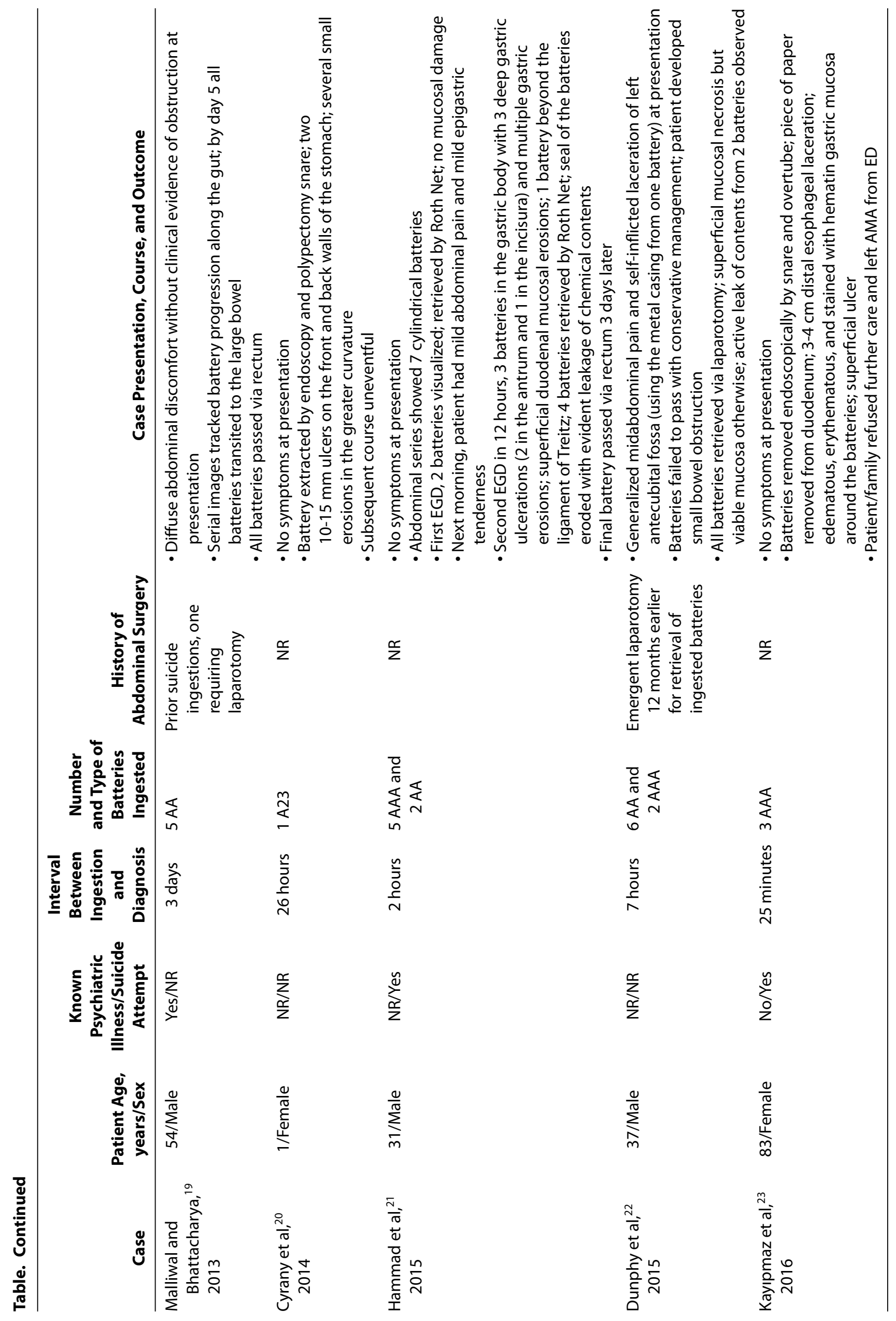




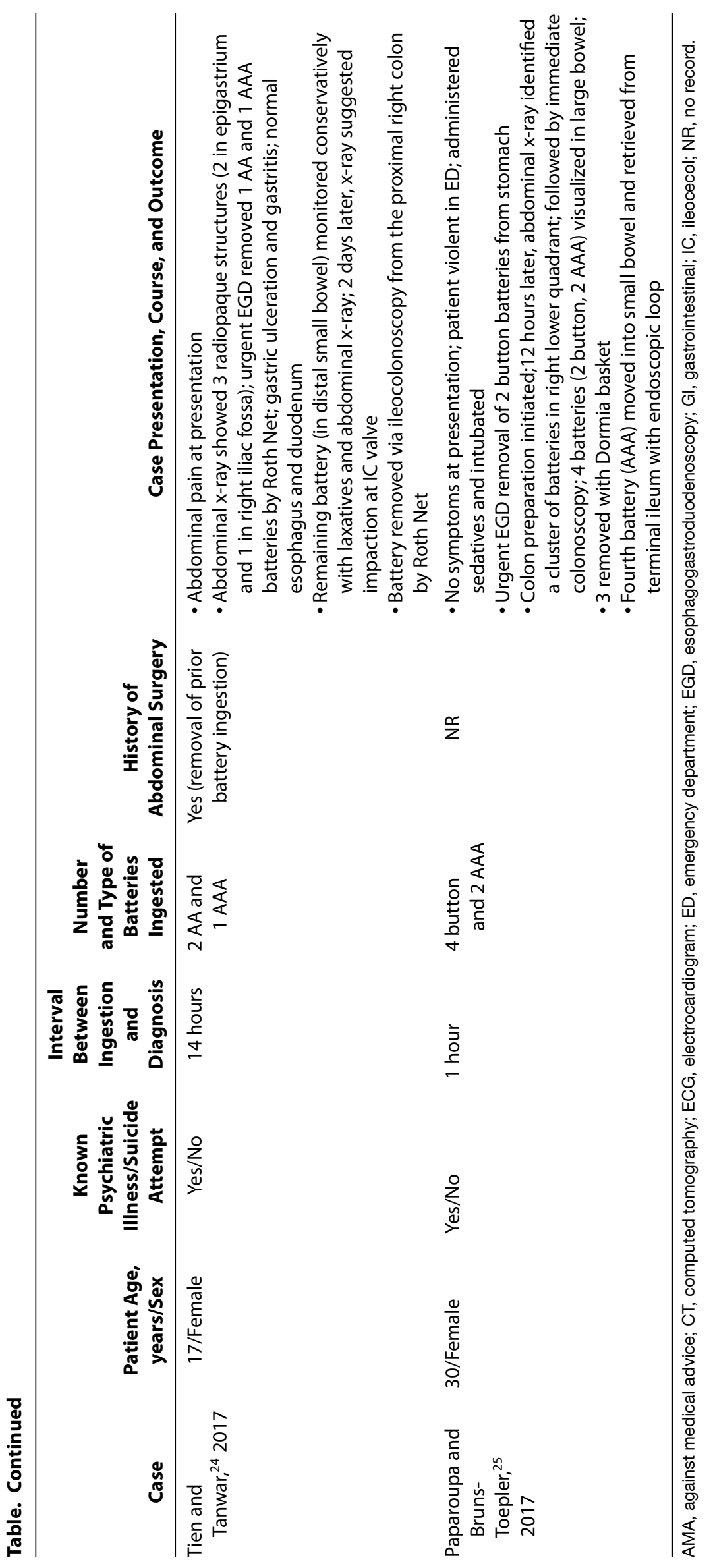


In an interesting report of delayed symptom presentation after battery ingestion, an individual who intentionally ingested 2 pairs of batteries wrapped in plastic to help move drug packets along the Gl tract sought medical attention 6 years later because he was setting off alarms at the airport and had started having heartburn and intermittent abdominal pain. ${ }^{15} \mathrm{He}$ had expelled all drug packets and 1 pair of batteries a few days after ingestion, but 1 battery packet was not expelled. Upper endoscopy revealed a pair of batteries wrapped in plastic in the stomach, no sign of leakage was seen, and the stomach looked intact. Endoscopic retrieval was unsuccessful because the plastic began to tear, but the batteries were retrieved laparoscopically.

Current guidelines only briefly address cylindrical battery ingestion. Overall, intact cylindrical batteries pose a low threat for caustic damage after ingestion, but because of their length $(>2.5 \mathrm{~cm})$ they may become entrapped in the stomach in children and adults. The recommendation for retrieval of this battery type includes situations in which (1) the battery has remained in the stomach more than 48 hours, (2) the patient develops signs of injury to the Gl tract, or (3) evidence indicates that the battery had an encasement defect prior to ingestion. ${ }^{1}$

In our case, the batteries were in the patient's stomach beyond the recommended 48-hour observation period. However, he remained asymptomatic, and no evidence indicated that the batteries were damaged or eroded. Based on our case and review of the literature, we conclude that if cylindrical battery swallowing is not accompanied by abdominal symptoms or abnormal physical examination findings, the battery cases were not damaged prior to ingestion, and the batteries are beyond retrieval with esophagogastroduodenoscopy, cylindrical battery ingestion can be managed conservatively with the aid of radiologic imaging, regardless of the timing of the observation period. Our case demonstrates that conservative management with close clinical monitoring is possible in a hospital setting.

Nonurgent upper endoscopy may be considered if the batteries are within reach of an upper endoscope. If upper endoscopic retrieval is not feasible, clinical monitoring and following battery progression through the Gl tract with serial abdominal radiographs until batteries are discharged via the rectum can be achieved. However, in cases of prior abdominal surgery, history or evidence of damage to the battery, or any clinical symptoms, prompt endoscopy and battery retrieval are indicated. If retrieval fails, surgical consultation should be done for those cases.

Given the complexity of cylindrical battery ingestion, the lack of data on this subject, and the large variety of cylindrical batteries available, more reviews and specific guidelines on this topic seem indicated. In our review of the cases, most ingested cylindrical batteries were the $A A$ and $A A A$ type. However, other cylindrical battery shapes and sizes (ie, N, C, and AAAA, some of which resemble button batteries) may warrant different guidelines.

\section{CONCLUSION}

Cylindrical battery ingestions are less common than button batteries, and data on the outcomes of these ingestions are limited. Based on our case and review of the literature, we conclude that if cylindrical battery swallowing is not accompanied by abdominal symptoms or abnormal physical exam- ination findings, the battery cases were not damaged prior to ingestion, and the batteries are beyond retrieval with esophagogastroduodenoscopy, cylindrical battery ingestion can be managed conservatively with the aid of radiologic imaging. However, in the presence of prior abdominal surgery, history or evidence of damage to the battery, or any clinical symptoms, prompt endoscopy and battery retrieval should be done. If this is not possible, then surgical consultation should be done for those cases.

\section{ACKNOWLEDGMENTS}

The authors have no financial or proprietary interest in the subject matter of this article.

\section{REFERENCES}

1. ASGE Standards of Practice Committee, Ikenberry SO, Jue TL, Anderson MA, et al. Management of ingested foreign bodies and food impactions. Gastrointest Endosc. 2011 Jun;73(6):1085-1091. doi: 10.1016/j.gie.2010.11.010.

2. Litovitz T, Schmitz BF. Ingestion of cylindrical and button batteries: an analysis of 2382 cases. Pediatrics. 1992 Apr; 89(4 Pt 2):747-757.

3. David TJ, Ferguson AP. Management of children who have swallowed button batteries. Arch Dis Child. 1986 Apr;61(4):321-322.

4. Gitlin DF, Caplan JP, Rogers MP, Avni-Barron O, Braun I, Barsky AJ. Foreign-body ingestion in patients with personality disorders. Psychosomatics. 2007 Mar-Apr;48(2): 162-166.

5. O'Sullivan ST, Reardon CM, McGreal GT, Hehir DJ, Kirwan WO, Brady MP. Deliberate ingestion of foreign bodies by institutionalised psychiatric hospital patients and prison inmates. Ir J Med Sci. 1996 Oct-Dec;165(4):294-296.

6. Litovitz T, Whitaker N, Clark L. Preventing battery ingestions: an analysis of 8648 cases. Pediatrics. 2010 Jun;125(6):1178-1183. doi: 10.1542/peds.2009-3038.

7. Untersweg U, Mayr J, Schmidt B. Oesophageal burn caused by sucking a 1.5 volt battery. Acta Paediatr. 1996 Nov;85(11):1382-1383.

8. Litovitz TL. Battery ingestions: product accessibility and clinical course. Pediatrics. 1985 Mar;75(3):469-476.

9. Litovitz T, Whitaker N, Clark L, White NC, Marsolek M. Emerging battery-ingestion hazard: clinical implications. Pediatrics. 2010 Jun;125(6):1168-1177. doi: 10.1542/peds.2009-3037.

10. Levine MJ, Jacob H, Rubin M. Battery ingestion: a potential form of alkaline injury to the gastrointestinal tract. Ann Emerg Med. 1984 Feb;13(2):143-145.

11. Young TL, Lubitz RM. Cylindrical battery ingestion: a case of endoscopic retrieval. J Tenn Med Assoc. 1989 Aug;82(8):415-416.

12. Kaplan G, Totten VY. Repeat cylindrical battery ingestion. Emerg Med. 1993 Dec;5(4):257-260. doi: 10.1111/j.1442-2026.1993.tb00116.x.

13. Hindley N, Gordon H, Newrith C, Mohan D. The management of cylindrical battery ingestion in psychiatric settings. Psychiatr Bull. 1999 Apr;23(4):224-226. doi: 10.1192/pb.23.4.224.

14. Lim JK, Kaltenbach TR, Sirinian E, Marcus SN. Endoscopic removal of two leaking alkaline batteries. Gastrointest Endosc. 2006 Mar;63(3):497; discussion 498.

15. Lavon O, Lurie Y, Abbou B, Bishara B, Israelit SH, Bentur Y. Surgical removal of cylindrical batteries 6 years after ingestion. Isr Med Assoc J. 2008 Nov;10(11):799-801. 
16. Nielsen SU, Rasmussen M, Hoegberg LC. Ingestion of six cylindrical and four button batteries. Clin Toxicol (Phila). 2010 Jun;48(5):469-470. doi: 10.3109/15563651003785591.

17. Ribakovs A, Uzoigwe C. From cylindrical battery ingestion to right hemicolectomy. Am Surg. 2011 Jun;77(6): 103-104.

18. Chang H, Hu SC, Tsai MJ. Cylindrical battery ingestion with electrocardiogram mimicking ST-segment elevation myocardial infarction. J Am Coll Cardiol. 2012 Jun 19;59(25):2387. doi: 10.1016/j.jacc.2011.11.073.

19. Malliwal RS, Bhattacharya S. Durable cell: a case of multiple AA battery ingestion as a mode of deliberate self-harm. JRSM Short Rep. 2013 Apr;4(4):28. doi: 10.1177/2042533313476681.

20. Cyrany J, Melek J, Dedek P, Toms J, Rejchrt S. Cylindrical battery ingested by a 1-year-old baby - does the voltage matter? Endoscopy. 2014;46 Suppl 1 UCTN:E543-E544. doi: $10.1055 / \mathrm{s}-0034-1377772$.
21. Hammad TA, Alastal Y, Bawany MZ, Nawras A, Hammad M, Alaradi O. Cylindrical batteries in the stomach: should we wait 48 hours for removal? ACG Case Rep J. 2015 Oct 9;3(1):3-4. doi: 10.14309/crj.2015.80.

22. Dunphy L, Maatouk M, Raja M, O'Hara R. Ingested cylindrical batteries in an incarcerated male: a caustic tale! BMJ Case Rep. 2015 Sep 29;2015. doi: 10.1136/bcr-2014-208922.

23. Kayıpmaz AE, Çelikel E, Ocal S, et al. A suicide attempt by ingestion of cylindrical batteries. J Surg Arts/Cerrahi Sanatlar Dergisi. 2016;9(1):43-45.

24. Tien T, Tanwar S. Ingestion of cylindrical batteries and its management. BMJ Case Rep. 2017 Jan 17;2017. doi: 10.1136/bcr-2016-218448.

25. Paparoupa M, Bruns-Toepler M. Foreign body moves retrograde through ileocecal valve during colonoscopy. Case Rep Gastrointest Med. 2017;2017:8707959. doi: $10.1155 / 2017 / 8707959$.

This article meets the Accreditation Council for Graduate Medical Education and the American Board of Medical Specialties Maintenance of Certification competencies for Patient Care and Medical Knowledge. 